\title{
Nipple Reduction Using an S-Shaped Excision Technique
}

\author{
Hyun Rok Lee, Gyu Yong Jung, \\ Dong Lark Lee, Hea Kyeong Shin \\ Department of Plastic and Reconstructive \\ Surgery, Dongguk University Gyeongju \\ Hospital, Dongguk University College of \\ Medicine, Gyeongju, Korea
}

No potential conflict of interest relevant to this article was reported.
Many people experience psychological distress because of large nipples. In this article, the authors would like to introduce our simple nipple reduction method that addresses the drawbacks of previous methods. This technique for nipple reduction using an Sshaped excision is simple, safe, and predictable. It is also a suitable method for nipple reduction in men and in women who have completed breastfeeding.

Keywords Mammaplasty, Nipples, Surgical flaps

\section{INTRODUCTION}

Men or women with large nipples may have problems with sexual relations, be afraid of taking off their clothes in public changing room, and/or feel uncomfortable when wearing tight clothing; these issues cause many people to experience emotional distress.

Although the ideal female nipple size has not been established, the reported average areolar diameter for Asian women is $4.0 \mathrm{~cm}$, the average nipple diameter is $1.3 \mathrm{~cm}$, and the average height is 0.9 $\mathrm{cm}$ [1]. Thus, the areolar diameter of Asian women is relatively small, but the nipple diameter is comparatively large, and for this reason, nipple reduction is more important in Asians than in other races [2]. However, many surgeons do not regard nipple reshaping to be as important as mammoplasty.

Many nipple reduction methods have been previously described, but complications such as sensory changes and delayed healing have been reported, the methods are complicated, and the outcomes are unpredictable [2-9]. In this article, the authors introduce an effective, safe, and straightforward nipple reduction method that ad-

Received: Dec 27, 2017 Revised: Feb 6, 2018 Accepted: Mar 1, 2018 Correspondence: Gyu Yong Jung Department of Plastic and Reconstructive Surgery, Dongguk University Gyeongju Hospital, Dongguk University College of Medicine, 87 Dongdae-ro, Gyeongju 38067, Korea.

E-mail: jnjbeauty@naver.com

Copyright @ 2018 The Korean Society for Aesthetic Plastic Surgery.

This is an Open Access article distributed under the terms of the Creative Commons Attribution Non-Commercial License (http://creativecommons.org/licenses/by-nc/4.0/) which permits unrestricted non-commercial use, distribution, and reproduction in any medium, provided the original work is properly cited. www.e-aaps.org dresses the above-mentioned drawbacks of previously described methods.

\section{IDEA}

\section{Surgical procedure}

To determine the amount of nipple tissue to remove, we agreed on an ideal nipple size and made the appropriate measurements preoperatively. Assuming that the ideal nipple size and mean size are the same, the ideal nipple shape was taken to be that of a gentle hemisphere on a cylinder with a diameter of $1.3 \mathrm{~cm}$ and height of $0.9 \mathrm{~cm}$ (Fig. 1).

In this case, the circumference of the ideal nipple cylinder was calculated as $1.3 \times 3.14 \mathrm{~cm}$, or almost $4 \mathrm{~cm}$. To create a nipple of this size, we designed two apposed flaps with an outer circumference of $2.0 \mathrm{~cm}$. Briefly, given a required nipple height of $0.9 \mathrm{~cm}, 2$ pairs of lines were drawn approximately $0.9 \mathrm{~cm}$ from the nippleareolar junction and then 2 matching S-shaped lines were drawn across the top of the nipple from the ends of these lines (Fig. 2). The 2 dog ears at the nipple-areolar junction were corrected by excising small triangular pieces of tissue.

The variable $M$ was defined as the width of tissue removed from the top of the nipple, and $N$ as the width of tissue removed from the side of the nipple. When the circumference of a nipple before surgery is $X, 2 N=X-4.0$. As shown in Fig. 2, the nipple diameter was designed to be $1.3 \mathrm{~cm}$, the height to be $0.9 \mathrm{~cm}$, and the circumference to be about $4.0 \mathrm{~cm}$ after surgery. The length of $M$ and $N$ may vary depending on the patient's preference.

After $M$ and $N$ were determined, sufficient tissue excision was 
performed to minimize tension after closure. Temporary sutures were placed at the highest points on both sides of the nipple to achieve the desired height, and irregular margins were trimmed according to the height and shape desired by the patient. Suturing was then performed using 6-0 Vicryl and 6-0 nylon sutures.

\section{DISCUSSION}

Several complex techniques have been devised for nipple reduction, but if multiple flaps are elevated or excessive excision is applied to the nipple base, subsequent sensory changes may occur [3]. In addition, because nipple blood supply is provided by the subdermal plexus, complex procedures can jeopardize blood supply

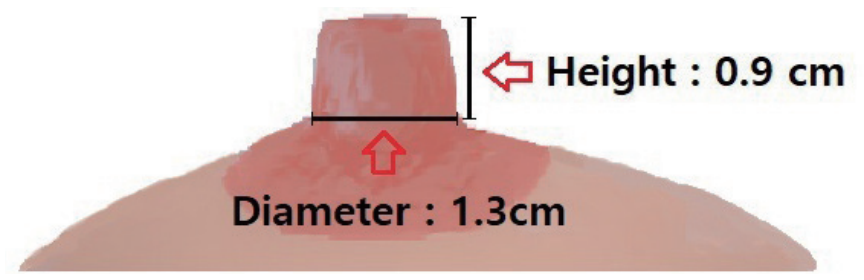

Fig. 1. Ideal nipple shape and size.

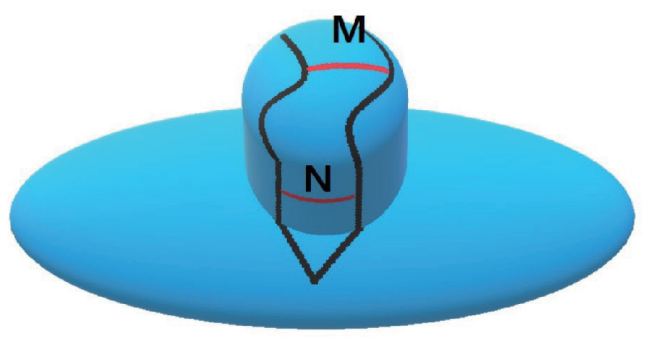

A

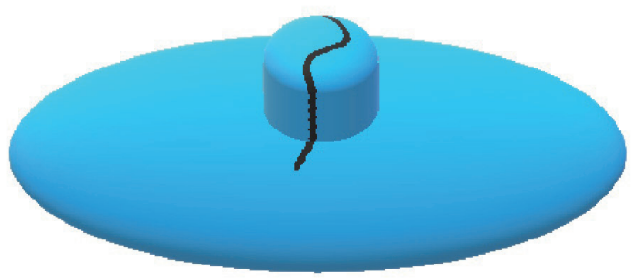

and cause delayed wound healing or necrosis $[5,6,8,10]$. From this point of view, we consider our method to be safer than previous methods, mainly because of its simplicity.

In addition, several procedures have been described that preserve lactation, but they provide ineffective nipple diameter reduction because the circumcision methods were designed to avoid the central area [4-6]. However, in previous studies the majority of patients who requested nipple reduction were either women with no intention of becoming pregnant or men, and the preservation of lactiferous ducts was therefore not an essential requirement. By using the described procedure, sufficient central parenchyma can be removed and the tension can be reduced by approximation, and the expected results satisfy patients' long-term expectation for nipple size. Additionally, other simple methods to remove other central areas of parenchyma are effective for height removal, but they do not reduce the diameter effectively. However, our method can also effectively reduce the diameter $[4,9]$.

An important advantage of our method is that it enables the height and circumference of the final product to be predicted, and based on our experiences, it produces results in accord with the preoperative calculations, allowing symmetrical nipples to be obtained by calculation even in the presence of asymmetry (Fig. 3).
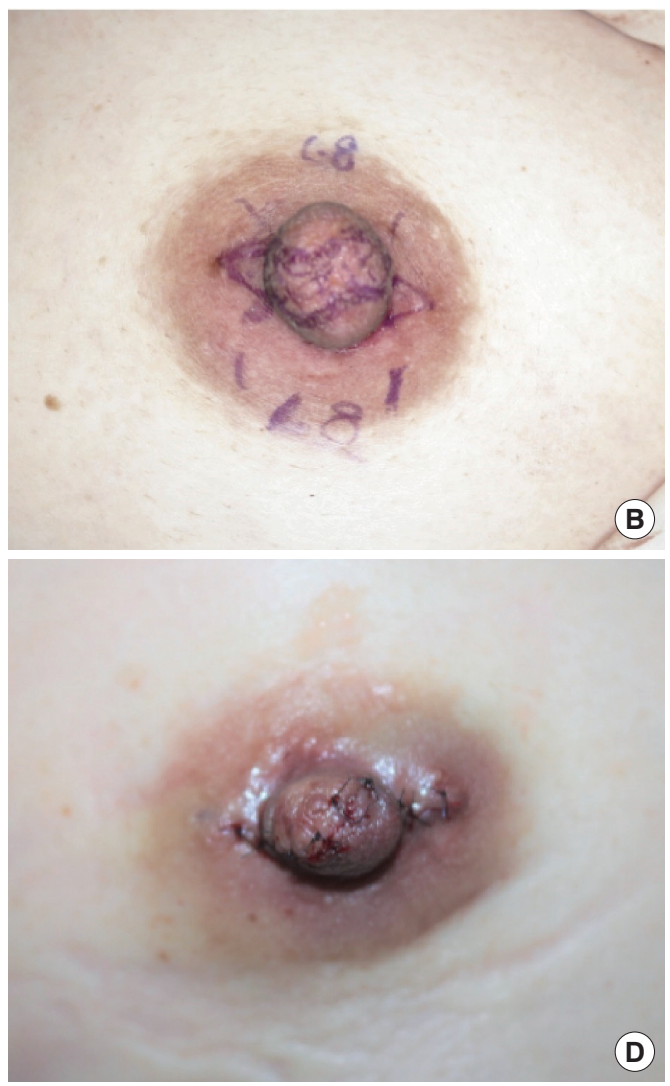

Fig. 2. Illustration of the procedure. (A, B) Preoperative design and measurements. (C, D) After closure. 

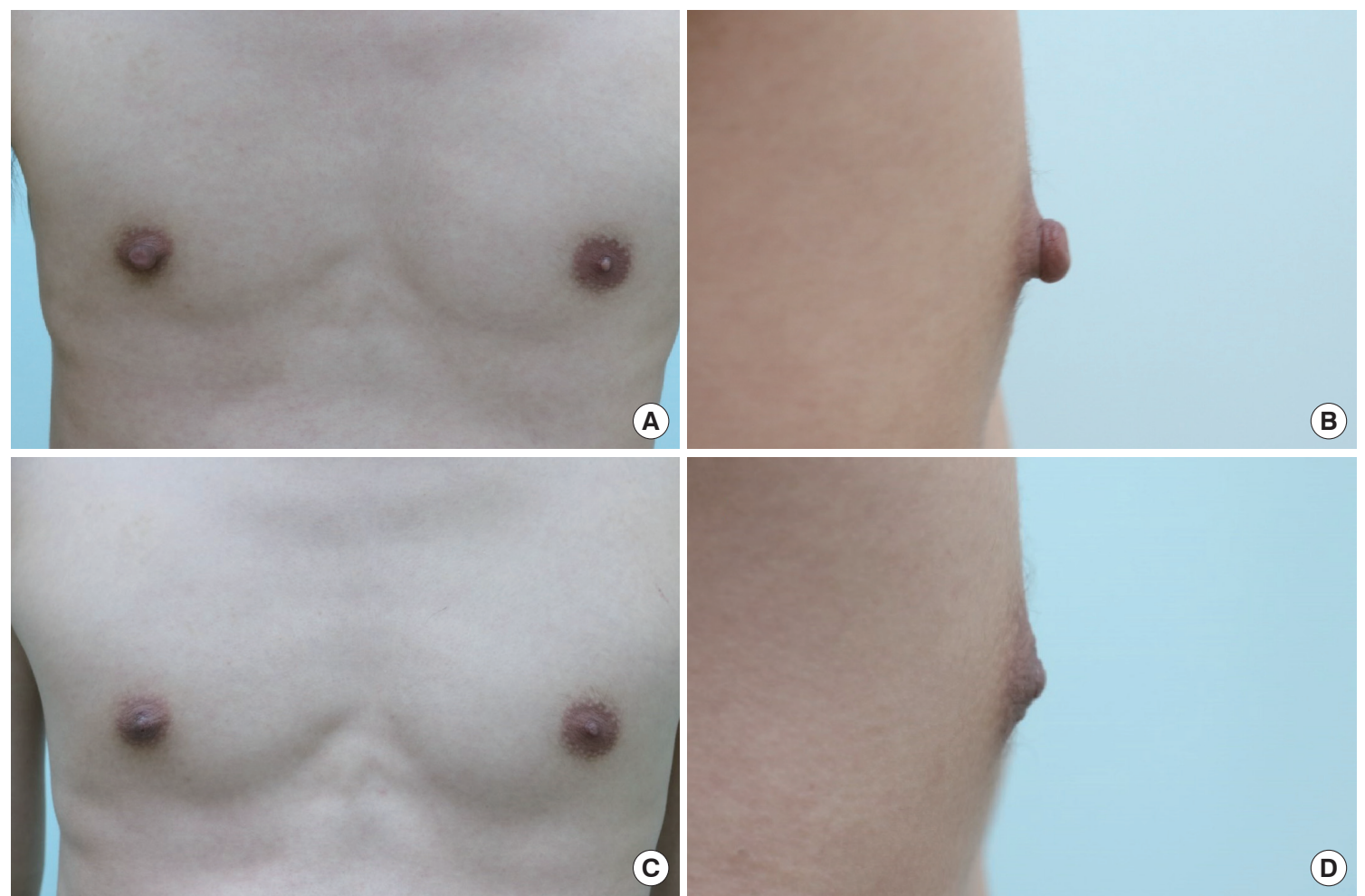

Fig. 3. Preoperative and postoperative views of a 21 -year-old man with right-side nipple hypertrophy and asymmetry. Right-side nipple reduction was performed. (A, B) Preoperative views. (C, D) Views at 6 months postoperatively showing a natural appearance.
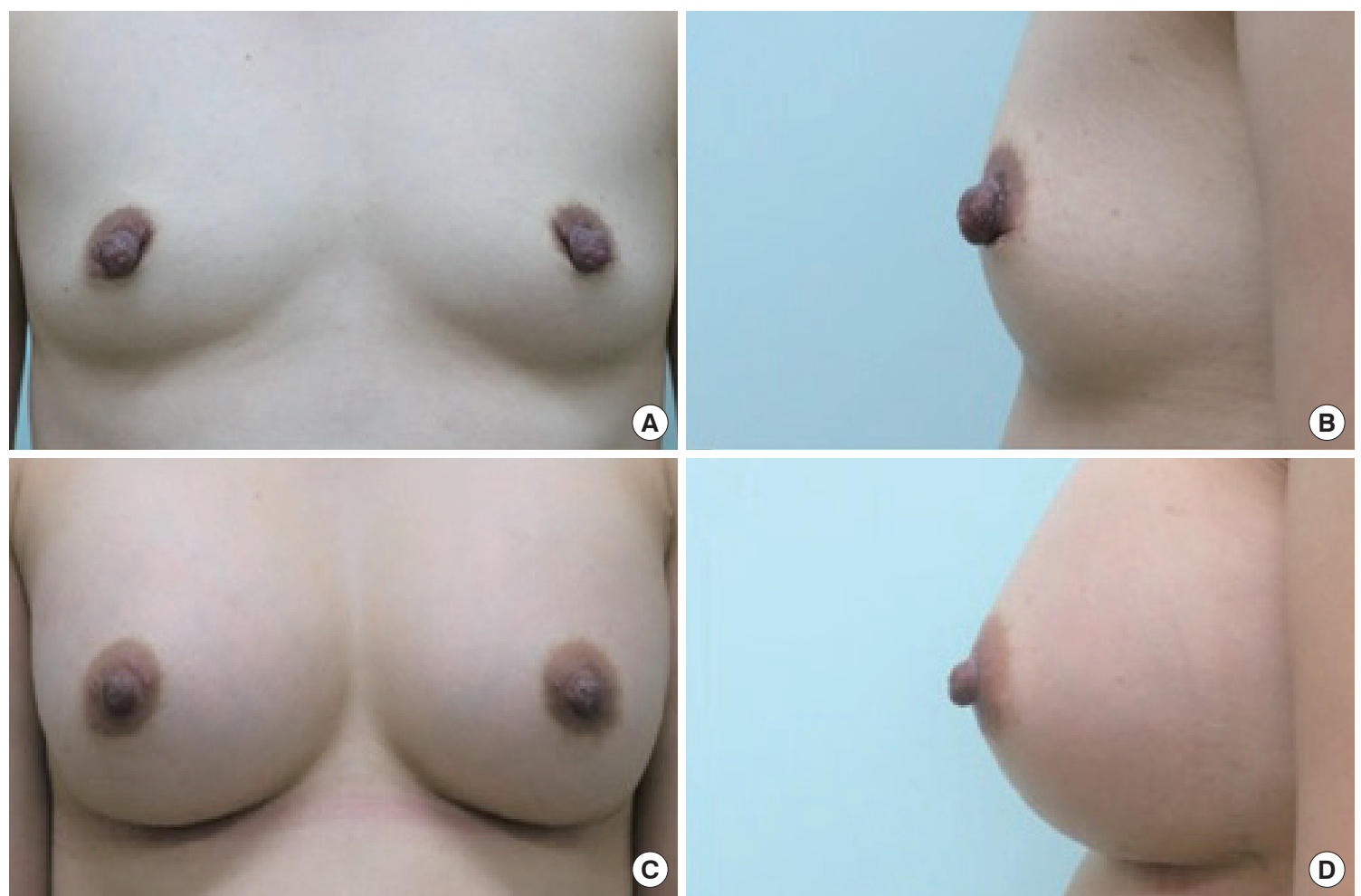

Fig. 4. Preoperative and postoperative views of a 36-year-old woman no longer seeking pregnancy. Augmentation mammoplasty and nipple reduction were performed. (A, B) Preoperative views. (C, D) Views at 6 months. 
However, the primary disadvantage of our method is that short scars at the nipple-areolar junction can occur in the areolar direction, but they are adequately disguised by Montgomery tubercles. In addition, to disperse the direction of scarring, we used an Sshaped incision. No patient has yet complained about scarring because the scars became invisible at around 6 months postoperatively (Fig. 4).

We conclude that the described S-shaped excision technique is both safe and straightforward and produces predictable results, and that it is suitable for nipple reduction in men and in women who have completed breastfeeding.

\section{PATIENT CONSENT}

Patients provided written consent for the use of their images.

\section{REFERENCES}

1. Sanuki J, Fukuma E, Uchida Y. Morphologic study of nipple-areola complex in 600 breasts. Aesthetic Plast Surg 2009;33:295-7.
2. Cheng MH, Ho-Asjoe M, Wei FC, et al. Nipple reconstruction in Asian females using banked cartilage graft and modified top hat flap. Br J Plast Surg 2003;56:692-4.

3. Sim HB, Sun SH. Nipple reduction with the chullo-hat technique. Aesthet Surg J 2015;35:NP154-60.

4. Jin US, Lee HK. Nipple reduction using circumcision and wedge excision technique. Ann Plast Surg 2013;70:154-7.

5. Lai YL, Wu WC. Nipple reduction with a modified circumcision technique. Br J Plast Surg 1996;49:307-9.

6. Ren M, Wang Y, Wang B. Nipple reduction using a three-dimensional Z-shaped incision technique. J Plast Reconstr Aesthet Surg 2013;66: 770-5.

7. Mu D, Luan J, Guo X, et al. Male nipple reduction with a simple circular-flap technique. Aesthet Surg J 2016;36:113-6.

8. Cheng MH, Smartt JM, Rodriguez ED, et al. Nipple reduction using the modified top hat flap. Plast Reconstr Surg 2006;118:1517-25.

9. Kim YS, Hwang K. Easy method for reduction of nipple height. Aesthetic Plast Surg 2010;34:769-72.

10. Stone K, Wheeler A. A review of anatomy, physiology, and benign pathology of the nipple. Ann Surg Oncol 2015;22:3236-40. 